\title{
EFFECTS OF THREE WATERTABLE TREATMENTS ON THE GROWTH OF THE AZUCENA RICE VARIETY
}

\author{
J.D. Owusu-Sekyere and N. Adu-Gyimah \\ School of Agriculture, University of Cape Coast, Cape Coast
}

\begin{abstract}
As the worlds fresh water dwindles, there are attempts to find more effective methods of irrigation. This issue is most important for lowland rice as water requirement for lowland rice production is about two times that required for production for other cereal crops. Growth of rice variety Azucena under three water treatments was studied: water table at $15 \mathrm{~cm}$ and $30 \mathrm{~cm}$ below the sand surface and a flooded treatment with a flood depth of $2 \mathrm{~cm}$ above ground. The root rhizosphere environment was also studied. The plants were grown for a period of six weeks and parameters determined included: tiller numbers, length of nodal roots, soil temperatures and total oxides of Nitrogen. The plants under the flooded treatment had a significantly greater number of tillers than the others. Availability of nitrogen (TON) was generally as follows: $15 \mathrm{~cm}$ water treatment $>$ flooded treatment $>30 \mathrm{~cm}$ water table treatment. Soil temperatures were significantly different under all the treatments. Lower water tables may not be suitable for the growth of the Azucena rice variety
\end{abstract}

Keywords: Water table control, Azucena, flooded treatment, nitrogen, temperatures

\section{INTRODUCTION}

As the worlds fresh water dwindles, there are attempts to find more effective methods of irrigation. This issue is most important for lowland rice as water requirement for lowland rice production is about two times that required for production for other cereal crops (CIGAR, 1999).

According to Owusu-Sekyere (2005), many irrigation methods have been applied to lowland rice, however, none of them has been able to im- prove upon rice productivity under basin irrigation and the search for alternative methods of rice irrigation continues. Water table control is a method that attempts to control the level of the water table for the purpose of crop production. It has been used on a number of crops and has been reported to lead to increased yield as well as water saving (Owusu-Sekyere, 1998). Water table control in rice production could lead to a modification of the root rhizosphere, because unlike 
flooded rice, where the root zone is saturated, there is a certain level of aeration under water table control conditions.

This paper reports on the effect of three water treatments on the growth of rice variety Azucena over a period of six weeks. Some soil rhizosphere parameters are also studied to determine if any differences in growth could be attributed to their changes.

\section{MATERIALS AND METHODS}

Water treatments

The treatments used in the experiments were:

1. Water table held at $15 \mathrm{~cm}$ below the sand surface $(15 \mathrm{~cm}$ treatment)

2. Water table held at $30 \mathrm{~cm}$ below the sand surface ( $30 \mathrm{~cm}$ treatment) and

3. Flooded soil with flood depth of $2 \mathrm{~cm}$. (Flooded treatment).

The water table depths were selected based on work done by Clark et al., (2002) who used a water table treatment to test the ability of rice roots to penetrate a hard pan.

\section{Experimental design}

The plants were grown in the cores, which were fitted into tanks in which the water table levels were controlled. A randomised complete block design with three replications was used. There were three tanks in each block, and each tank had six cores. These cores were filled with the growth material and placed in the tanks. The environment in the growth chamber was controlled. Blocking was used due to variations on levels of incident radiation in different areas of the growth chamber.

\section{Growth chamber}

The experiments were conducted in growth chambers at the Silsoe Research Institute, Silsoe, U.K., under controlled environment. The controlled conditions were: 16 hour day length, $30^{\circ} \mathrm{C}$ air temperature during the day and $26^{\circ} \mathrm{C}$ at night, a relative humidity of air of $70 \%$ and a photosynthetic photon flux density of $300-350 \mathrm{~mol} \mathrm{~m}^{-2} \mathrm{~s}^{-1}$ provided by fluorescent tubes, supplemented by tungsten bulbs.

\section{Core arrangement}

The cores, made of plastic, were $45 \mathrm{~cm}$ long and $15.2 \mathrm{~cm}$ in internal diameter. Six of them were fitted into each tank. In setting up, the bottom of the cores were covered with permeable cloth and placed directly into the tank; they were then filled with sand. The cloth prevented sand from falling out and helped to retain the sand and plant in the core during harvesting. The sand was initially saturated with nutrient solution, and the cores were gently tapped as the solution was added to ensure that the sand surface was level. Nutrient solution was poured into the tanks, around the cores.

\section{Water supply}

The water was supplied through the bottom of the core and the plants were watered by capillary action. The water table was initially held at a depth of $30 \mathrm{~cm}$ below the soil surface in each of the tanks to ensure seedling establishment. The treatments were imposed three days after sowing, when the plants were about $2 \mathrm{~cm}$ high, by adding more nutrient solution to raise the water levels in the tanks to their respective depths. The depth of the water table was held at the specified depths throughout the experiment by topping up at least every two days. A mean drop of about $1 \mathrm{~cm}$ a day in the level of the solution was observed, thus when topping up, the level of the solution was raised $1 \mathrm{~cm}$ above the desired level so that over the two days, the mean depth would be the desired depth. Flow of water into the cores was not in any way inhibited by the permeable cloth; this was determined by observing increase and decrease of depth of floodwater in the cores subjected to the flooded treatment.

\section{Nutrient solution}

A nutrient solution of composition $1.5 \mathrm{mM} \mathrm{Ca}$ $\left(\mathrm{NO}_{3}\right)_{2}, 0.15 \mathrm{mM} \mathrm{CaH} 4(\mathrm{PO} 4)_{2}, 1.0 \mathrm{mM} \mathrm{KCL}, 0.3$ $\mathrm{mM} \mathrm{MgSO}$, with the following micronutrients: $50 \mathrm{~m} \mathrm{M} \mathrm{B,} \mathrm{50m} \mathrm{M} \mathrm{Fe,} \mathrm{10mM} \mathrm{Mn,} 1 \mathrm{mM} \mathrm{Zn,}$ 
$1 \mathrm{mM} \mathrm{Cu}$ and $0.5 \mathrm{mM}$ Mo (Clark et al., 2002) was used.

\section{Growth medium}

Sand was used as the growth medium. It was selected primarily to test the feasibility of rice growing under the conditions imposed without the influence of other factors that might have been introduced with the soil. It was also selected because control of the water table depth under sand, due to the higher hydraulic conductivity of sand, was easier than under heterogeneous soils and this was desired in a first attempt at such an experiment.

\section{Germination}

Azucena rice variety, seeds were used. The seeds were placed in petri dishes (germination requires some moisture) lined with slightly soaked filter paper and wrapped in aluminium foil to exclude light, and kept for 5 days under a 14-hour day with day temperatures of $30^{\circ} \mathrm{C}$ and night temperatures of $20^{\circ} \mathrm{C}$ for germination.

\section{Sowing}

Sowing was done by placing pre-germinated seedlings in small holes about $1 \mathrm{~cm}$ deep, with the coleoptile protruding from the surface. The seedlings were carefully covered and vermiculite placed around the base of the seedling. This was to ensure that the seedling did not dry out. Vermiculite is able to absorb moisture so it is able to keep its surroundings moist as long as there is a moisture supply.

\section{Harvesting}

The tanks were drained at each harvest before the cores were lifted out to avoid the breakage of the roots. The cores containing the plants and the growth medium were put into the harvesting equipment (Clark et al., 2002) and the cores pulled out leaving the plant and the sand. The sand was washed away and the plant removed. The plants were stored in a refrigerator and measured at a later date. A ruler was used to determine the length of each root and the shoot. In the case of the roots, each root was straightened and the ruler used to determine its length. The plants were dried in an oven for 18 hours at a temperature of $102^{\circ} \mathrm{C}$ and the root and shoot dry mass determined by weighing.

\section{RESULTS AND DISCUSSION \\ Root length greater than $30 \mathrm{~cm}$}

According to Samson et al., (2002) oxygen supply via aerenchyma restricts rice roots to surface layers when the soil is flooded and the soil remains essentially anaerobic. Naklang et al. (1996) concluded that root growth of upland rice was much less than that of lowland crops, indicating the sensitivity of root growth to soil water deficit. Root length above $30 \mathrm{~cm}$ is used as an indication of the extent to which the roots can explore deeper depths of soil for water and nutrients. In upland rice, farmers have traditionally used varieties with deep root systems that can avoid drought by extracting more water from deeper soil layers (Puckridge and O'Toole, 1981). Barison (2002) attributed greater uptake of nutrients of rice under the System of Rice Intensification (SRI) to the fact that there were more roots greater than $30 \mathrm{~cm}$ long.

From Figure 1, though there were more roots greater than $30 \mathrm{~cm}$ for the flooded treatment at the end of 6 weeks, the sum of the lengths of the roots was lower than for the $30 \mathrm{~cm}$ water table depth treatment, implying the mean length of roots was greater in the case of the plants under the $30 \mathrm{~cm}$ treatment. Right from the $2^{\text {nd }}$ week, the total root length for the $30 \mathrm{~cm}$ treatment stayed higher than the others. The plants under the 30 $\mathrm{cm}$ water table depth treatment had a greater potential to access moisture at lower depths.

\section{Tiller numbers}

The number of tillers is approximately constant for any variety of rice under comparable conditions, but tillering is influenced by cultural conditions, spacing of plants, amount of nitrogen fertiliser applied, weeds and water supply (Grist, 1986). Some of the conditions, which varied in 
this experiment, were the water supply and the amount of available nutrients in the different water table depths used which led to different levels of nutrients in the cores.

From Fig 2, at the end of the fourth week, there were no significant differences in number of tillers for the different water treatments. At the end of the sixth week, the number of tillers for the plants under the flooded conditions was significantly greater than that for the other treatments. Development of tillers slowed down dramatically for the plants under the $15 \mathrm{~cm}$ and $30 \mathrm{~cm}$ water table depth treatments whereas it increased for the plants under the flooded treatment from the fourth to the sixth week.

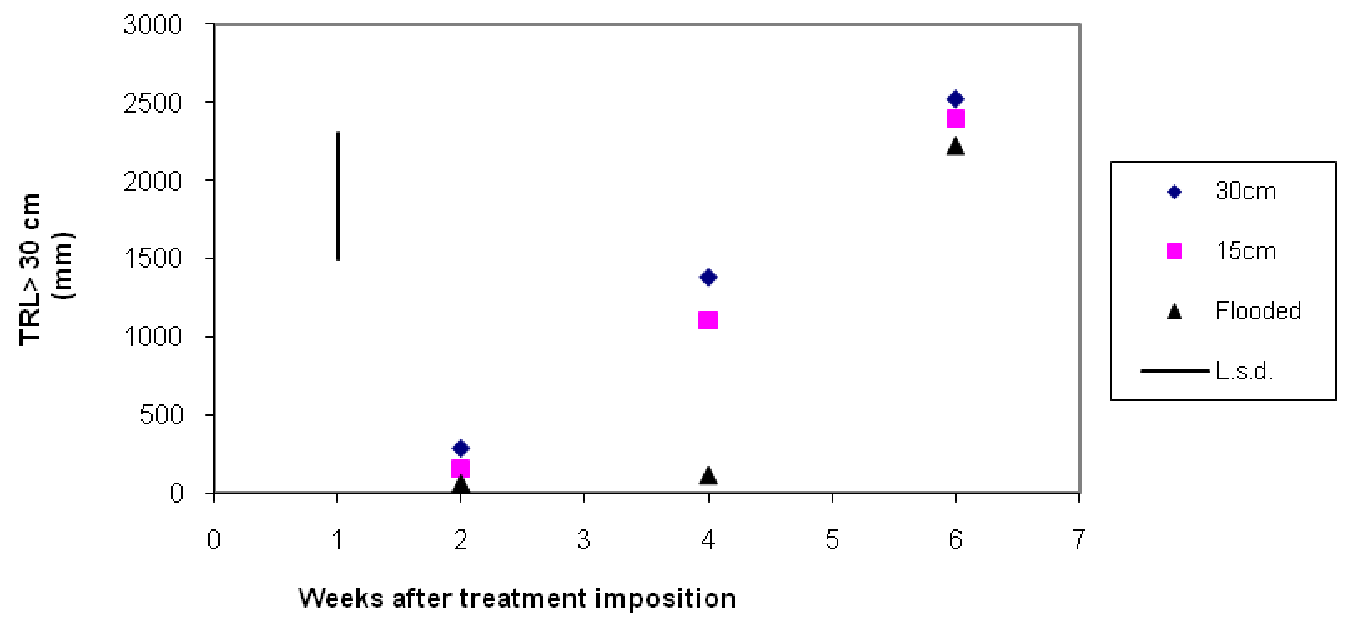

Figure 1: Total root length (TRL) greater than $30 \mathrm{~cm}$ vs weeks after treatment imposition, showing L.s.d. $(p<5 \%)$

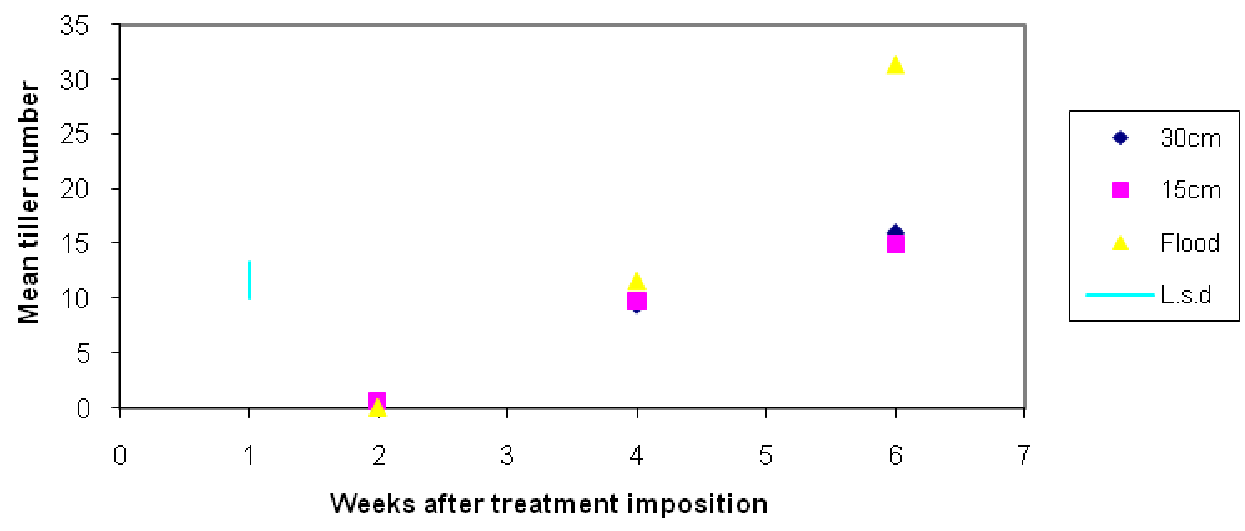

Figure 2: Mean tiller number vs. weeks after treatment imposition showing L.s.d. (p < 5\%)

42 Journal of Science and Technology, Vol. 29, No. 1, April, 2009 


\section{Sand Temperatures}

Soil temperature affects plant growth indirectly by affecting water and nutrient uptake as well as root growth. At a constant moisture content, a decrease in temperature results in a decrease in water and nutrient uptake. In this case there is a certain level of complexity in that there are three different moisture levels leading to three different temperature regimes and therefore different levels of influence in growth.

Temperatures were determined at two depths: 1 $\mathrm{cm}$ and $10 \mathrm{~cm}$ below the surface. This was done in order to obtain an idea of the temperature gradient in the rooting zone. Temperatures were significantly different for the different treatments at each depth; they were not significantly different between the two depths in any of the treatments.

Generally soils with a deeper water table heat up faster than those with a shallower water table (Hillel, 1980) and there is such a reflection here in that the treatments with the deeper water table depths were significantly hotter than those with the shallower water table depths.
The actual differences in temperatures were quite small, about $0.5^{\circ} \mathrm{C}$ between the $30 \mathrm{~cm}$ and the 15 $\mathrm{cm}$ water table treatments, and $1.25^{\circ} \mathrm{C}$ between the $15 \mathrm{~cm}$ and flooded treatments however, Songfa (1995) observed differences in growth of rice for temperature differences of between 0.2 and $0.4^{\circ} \mathrm{C}$, with the higher temperatures producing better growth. There is therefore the possibility that temperatures will contribute to differences in growth both directly and also through the influence on soil chemical properties.

Differences in temperatures between TOP and BOT varied for the different water treatments. The differences were significant between the 30 $\mathrm{cm}$ water table depth treatment and the flooded treatment. These differences reflected moisture gradients; greatest under $30 \mathrm{~cm}$ depth followed by $15 \mathrm{~cm}$ and the flooded. Soil temperature gradients increased with decreasing moisture contents.

According to Hillel (1980), the volumetric heat capacity for sand of volumetric moisture content of $0.0,0.2$ and 0.4 are $0.3,0.5$ are $0.7 \mathrm{~J} \mathrm{~cm}^{-3}{ }^{\circ} \mathrm{C}^{-1}$, respectively. The volumetric heat capacity is the amount of heat required to raise unit volume of

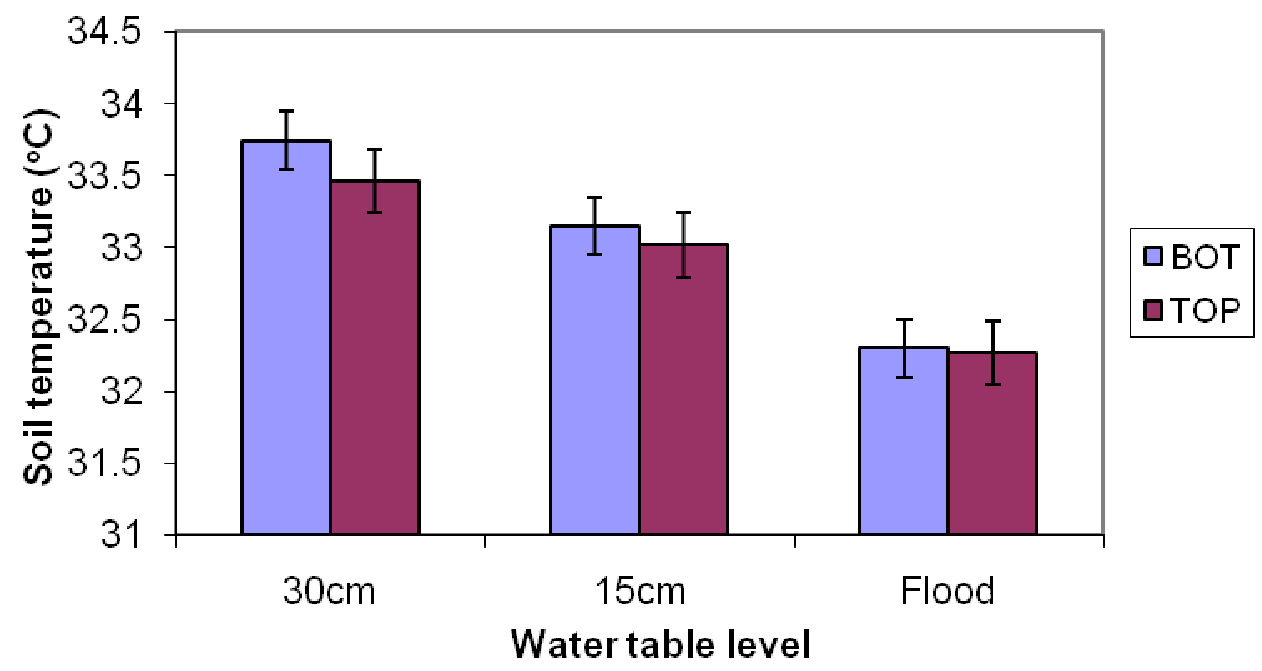

Figure 3: Soil temperature at depths of $1 \mathrm{~cm}$ (TOP) and $10 \mathrm{~cm}$ (BOT) from surface showing L.s.d. $(\mathbf{p}<5 \%)$ 


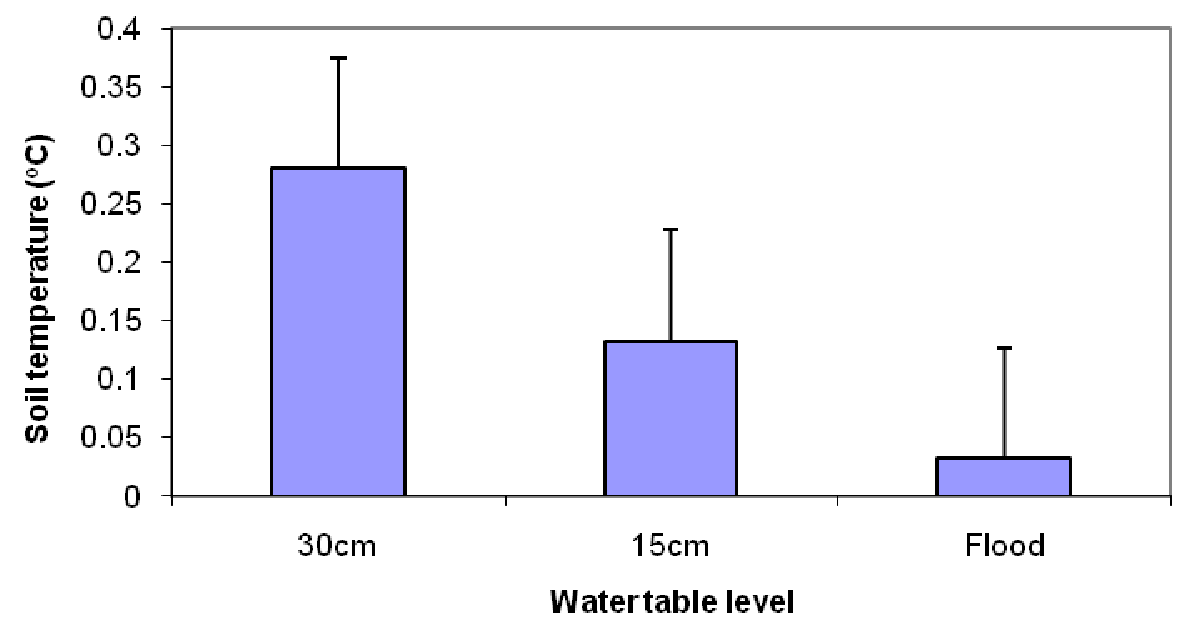

Figure 4: Mean difference in temperature $\left({ }^{\circ} \mathrm{C}\right)$ between soil surface and depth $10 \mathrm{~cm}$ below the surface for three water table levels with $Y$ error bars for L.s.d. $(p=5 \%)$.

soil by $1^{\circ} \mathrm{C}$. Owusu-Sekyere (2005) observed that under similar conditions, the volumetric moisture content for the $30 \mathrm{~cm}$ water table depth was 16.1 $\% ; 33.8 \%$ for the $15 \mathrm{~cm}$ water table depth and $44.4 \%$ for the flooded treatment.
Figure 5 is a plot of the volumetric heat capacities against volumetric moisture content according to Hillel (1980). The volumetric heat capacities for the moisture contents obtained in this experiment may then be estimated, which are: 0.36 for the 30

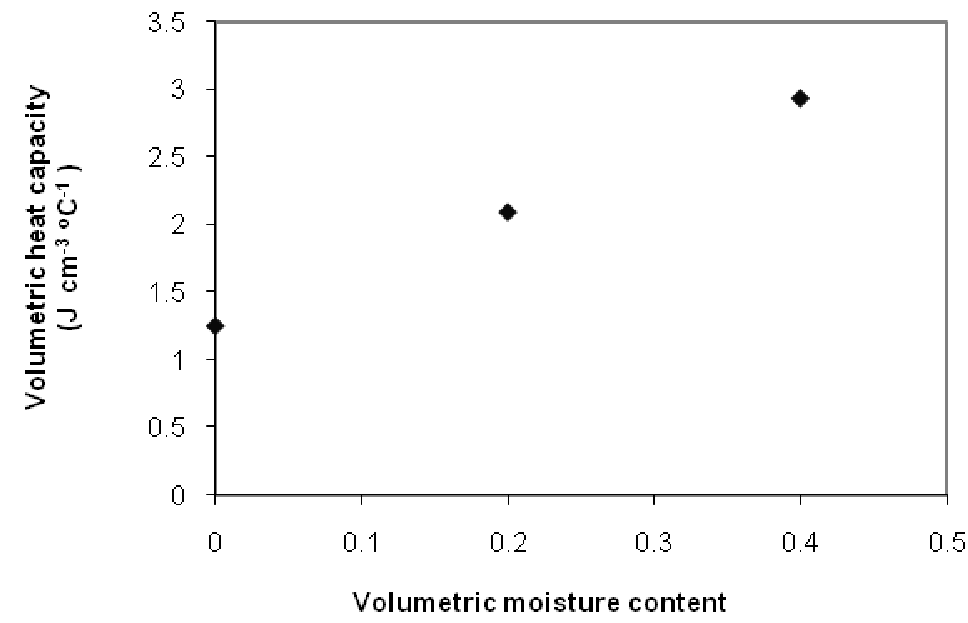

Figure 5: Volumetric heat capacity $\left(\mathrm{J} \mathrm{cm}^{-3}{ }^{\circ} \mathrm{C}^{-1}\right)$ vs volumetric moisture content. (Values adapted from Hillel (1980)

44 Journal of Science and Technology, Vol. 29, No. 1, April, 2009 
$\mathrm{cm}$ water treatment, 0.638 for the $15 \mathrm{~cm}$ water table treatment and 0.744 for the flooded treatment. It would thus require two times as much heat to raise the temperature of a volume of growth medium by $1^{0} \mathrm{C}$ in a flooded system than would be required for a water table depth of 30 $\mathrm{cm}$. Thus, even though there would be more heat under the flooded system, this would not be reflected in the temperature values.

\section{Total Oxides of Nitrogen (TON)}

Total oxides of nitrogen in this report refer to $\mathrm{NO}_{3}^{-} ; \mathrm{NO}_{2}^{-}$and $\mathrm{N}_{2} \mathrm{O}$. Levels of $\mathrm{NO}_{2}^{-}$determined were very low, relatively, (at about $0.1 \mathrm{mg} \mathrm{L}-1$ ) and were assumed to be negligible, $\mathrm{N}_{2} \mathrm{O}$ was not measured and $\mathrm{NO}_{3}{ }^{-}$is therefore used interchangeably with TON in the rest of the report.

It has been alluded to that differences in moisture content may not explain differences in growth of the plants under the conditions imposed. Moisture content will, however, influence other factors, which will have a greater impact on growth. The main determining growth factor then could be level of nitrogen available. It has already been noted that constituents of growth are dependant on levels of nitrogen available. As different levels of nitrogen are available under different levels of the water table, growth differences are expected to appear under the different depths of the water table primarily as a result of differences in levels of nitrogen available.

Mean values of TON $\left(\mathrm{NO}_{3}-\mathrm{N}\right)$ under a water table depth of $15 \mathrm{~cm}$ was significantly greater than for the flooded treatments as well as for the plants under the $30 \mathrm{~cm}$ water table depth. $\mathrm{NO}_{3}{ }^{-}$under the flooded treatments were higher than for the plants under the $30 \mathrm{~cm}$ treatment, this was however not significant.

Figure 7 shows values for $\mathrm{NO}_{3}{ }^{-}$at different times during the experiment. Though Fig 6 shows that there were significant differences in $\mathrm{NO}_{3}{ }^{-}$levels, these appeared only in the third and fourth weeks. After the third week there was a rise in the amount of nitrogen under the $15 \mathrm{~cm}$ water table treatment.

The plot of TON over time (Figure 7) shows that the flooded treatment started at the highest point

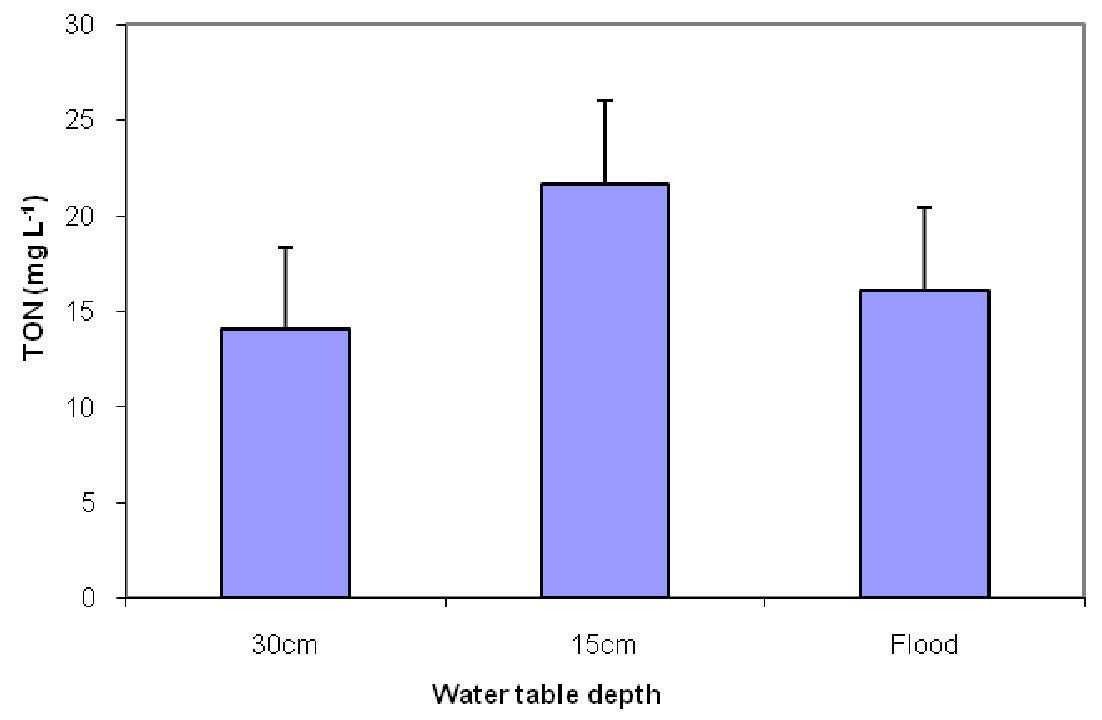

Figure 6: TON against water table depth with error bars representing L.s.d. $(p=5 \%)$ 


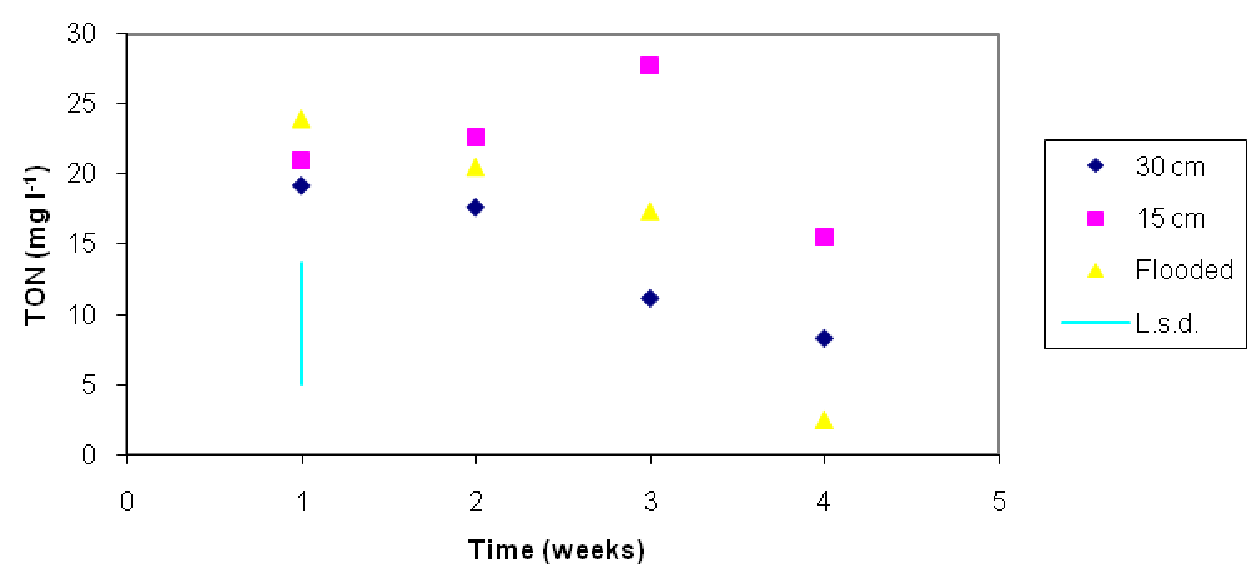

NO TITLE GIVEN

and dropped over time. The $15 \mathrm{~cm}$ treatment started a little lower but instead of decreasing, increased initially before finally dropping. The 30 $\mathrm{cm}$ treatment started out lowest and dropped but at a slower rate. Plant nitrogen content was not measured and so it is not possible to determine if the drop in nitrate levels for the flooded treatment was as a result of de-nitrification or uptake by the plant. Moreover, water use was also not measured, as that would also give an indication of uptake.

Utilisation of nitrates under the $15 \mathrm{~cm}$ water table depth plants was lower than in the other treatments leading to the lower results than for the plants under the $30 \mathrm{~cm}$ water table depth treatment in the third experiment. The drop for the flooded treatment could also be attributed to high levels of uptake leading to the large increase in shoot dry mass from the $4^{\text {th }}$ to the $6^{\text {th }}$ week.

\section{CONCLUSION}

Growth of Azucena rice variety was significantly better under flooded conditions as indicated by the number of tillers produced at the end of six weeks indicating that water table control may not be a good irrigation method as flooding for
Azucena rice variety. It is however apparent that there is some moisture saving when the water table is lowered. It may be necessary to grow rice up to yield to determine if moisture saving offsets yield loss.

\section{REFERENCES}

Barison, J. (2002). Evaluation of nutrient uptake and nutrient-use efficiency of SRI and conventional rice cultivation methods in Madagascar. Cornell International Institute for Food, Agriculture and Development. Accessed from http://ciifad.cornell.edu/sri; 607255-0831

Consultative Group on International Agricultural Research (CIGAR) (1999). New Rice Techniques Promise up to 25 Percent Less Water Usage. World Bank, Press Release. Accessed from http://www.worldbank.org/html/cgiar/ press/pres 0599.html

Clark, L.J., Cope, R.E., Whalley, W.R., Barraclough, P.B. and Wade, L.J. (2002). Root penetration of strong soil in rainfed lowland rice: comparison of laboratory screens with field performance. Field Crops Research 76: 189-198. 
Grist, D.H. (1986). Rice, Tropical Agriculture Series, sixth edition, Longman Ltd London, $601 \mathrm{pp}$.

Hillel, D. (1980). Applications of Soil Physics, Academic Press Inc. London, 385 pp.

Naklang, K., Fukai, S. and Nathabut, K. (1996). Growth of rice cultivars by direct seeding and transplanting under upland and lowland conditions. Field Crops Research 48: 115123.

Owusu-Sekyere, J.D. (1998). Study on Moisture Control in Wheat Fields Through Experimentation, Simulation and Optimization, an unpublished MSc. Thesis, Nanjing, China, 112 pp.
Owusu-Sekyere, J.D. (2005) Water Table Control For Rice Production in Ghana, an unpublished $\mathrm{PhD}$ Thesis, Cranfield University, Silsoe, U.K., 212 pp.

Puckridge, D.W. and O'Toole, J.C. (1981). Dry matter production of rice using a line source sprinkler in drought studies: Fields Crops Research 3: 303-319.

Samson, B.K., Hassan, M. L., Wade, J. (2002). Penetration of hardpans by rice lines in rainfed lowlands: Field Crops Research 76:175188.

Songfa, S. (1995). Development of Rice-Fish Farming in Guizhou Province Rice-Fish Culture in China, IDRC, $240 \mathrm{pp}$. 